\title{
Blockade of irradiation-induced autophagosome formation impairs proliferation but does not enhance cell death in HCT-116 human colorectal carcinoma cells
}

\author{
ANA CRISTINA DE ALBUQUERQUE-XAVIER ${ }^{1,4}$, LILIAN GONÇALVES R. BASTOS ${ }^{1}$, \\ JULIO CESAR MADUREIRA DE FREITAS Jr ${ }^{1}$, FERNANDA LEVE ${ }^{1}$, WALDEMIR FERNÁNDEZ DE SOUZA ${ }^{1}$, \\ WALLACE MARTINS DE ARAUJO ${ }^{1}$, JOÃO LUIZ MENDES WANDERLEY ${ }^{2}$, MARCELO NEVES TANAKA ${ }^{1}$, \\ WANDERLEY DE SOUZA ${ }^{3}$ and JOSÉ ANDRÉS MORGADO-DÍAZ ${ }^{1}$
}

\begin{abstract}
${ }^{1}$ Division of Cellular Biology, Jose Alencar National Cancer Institute; ${ }^{2}$ Division of Experimental Medicine, Jose Alencar National Cancer Institute and Pólo Universitário of Federal University of Rio de Janeiro; ${ }^{3}$ Department of Cellular Biology and Parasitology, Carlos Chagas Biophysic Institute, Federal University of Rio de Janeiro, Rio de Janeiro, RJ, Brazil
\end{abstract}

Received September 12, 2011; Accepted October 26, 2011

DOI: $10.3892 /$ ijo.2012.1329

\begin{abstract}
This work was undertaken to gain further information on the molecular mechanisms underlying autophagosome formation and its relation with tumor cell survival in response to radiation in colon cancer. A human colon cancer cell line, HCT-116, was examined with respect to cell survival after blockade of irradiation-induced autophagosome formation by pharmacological interference. Autophagosome formation was confirmed using a kinetic study with incorporated bovine serum albumin gold-conjugate (BSA-Au) analyzed by electron microscopy and an autophagosome-associated LC3B antibody measured by immunofluorescence and Western blotting. Annexin V/PI double staining was used to monitor cell death by apoptosis, and cell cycle profiles by flow cytometry. Ionizing radiation (IR) promoted autophagosome formation in the HCT-116 IR-surviving cells. Pharmacological interference showed that PI3K/Akt and Src were involved in early stages of autophagosome formation. IR alone decreased cell proliferation by arresting cells in the $\mathrm{G}_{2} / \mathrm{M}$ phase, and pharmacological interference of autophagosome formation decreased proliferation, but did not affect cell survival. Also, our data suggest that decreased proliferation caused by PI3K and Src inhibitors could be through S phase cell cycle delay. Our results clearly
\end{abstract}

Correspondence to: Dr José Andrés Morgado-Díaz, Division of Cellular Biology, Jose Alencar National Cancer Institute, Rua André Cavalcanti, 37-5 ${ }^{\circ}$ Andar, 20231-050, Rio de Janeiro, RJ, Brazil

E-mail: jmorgado@inca.gov.br

Present address: ${ }^{4}$ Medical Information Department GlaxoSmithKline Oncology, Estrada dos Bandeirantes 8464, 22783-110, Rio de Janeiro, RJ, Brazil

Key words: autophagy, colorectal cancer, radiotherapy, cell signaling, proliferation indicate that blockade of IR-induced autophagosome formation impairs proliferation but does not enhance cell death in colon cancer cells.

\section{Introduction}

Autophagy is a genetically and evolutionarily conserved process that occurs in all eukaryotic cells from yeast to mammals, which is used for the non-selective removal of long-lived proteins, large protein aggregates, and subcellular organelles (1-3). At the beginning of autophagy, portions of the cytoplasm and intra-cellular organelles are sequestered in double membrane-bound structures to form autophagosomes. Subsequently, they fuse with lysosomes to form autophagolysosomes, where the sequestered content is degraded by lysosomal hydrolases or recycled (4).

There is increasing evidence describing the role of autophagy in cancer (5), and various antineoplastic therapies were reported to induce autophagy in human cancer cell lines (6-8). However, fundamental questions regarding whether autophagy kills cancer cells or protects them from unfavorable conditions have not yet been clearly answered (9). Some studies have suggested an inverse relationship between autophagy and malignant growth, as Beclin 1, a key autophagy protein regulator, is a haploinsufficient tumor suppressor gene in mice $(10,11)$ but is frequently absent in human cancers (12). Also, the identification of damage-regulated autophagy modulator (DRAM), a protein necessary to induce p53-dependent autophagy, provides another link between autophagy and tumor suppression (13). Therefore, these studies suggest that defects in autophagy may favor carcinogenesis and that the restoration of autophagy may have promising therapeutic implications in cancer (14). However, there is no specific cancer therapy that targets autophagy in colorectal cancer, consequently a better understanding on the molecular mechanisms by which carcinogens lead to autophagy may contribute to the advancement of a rational clinical therapy in this cancer type. 
Autophagy is a multistep process, and various signaling pathways have been implicated in its upregulation and/or downregulation $(2,3,15)$. Nevertheless, independently whether the cell is normal or malignant, the mammalian target of rapamycin (mTOR) serves as the main regulator of autophagy (16). Oncogenic forms of Ras are also implicated in the negative control of autophagy through the activation of class I PI3K (17), and PTEN, the classic negative regulator of PI3K, regulates autophagy suppressing Akt activity leading to autophagy initiation (18). The mitogen-activated kinases (MAPKs) also were reported to regulate autophagy in cancer cells (19). Thus, various signaling pathways may control autophagy, but it is not fully understood if these pathways induce or suppress autophagy formation depending on the cell type. In epithelial tumor cells, such as breast, prostate, and colon cancer cells, it was reported that irradiation induced autophagosome formation, but apoptosis has little or no role in cell death (20-22). However, the cell signaling events underlying the formation of these organelles after IR, particularly in colon cancer cells has been only slightly explored, and it remains unclear if autophagy inhibition contributes to cell death.

Therefore, we hypothesized that IR promotes autophagosome formation in an event mediated by cell signaling pathways activated by this cancer therapy and that autophagy inhibition could lead to cell death. To test this hypothesis, we used the highly invasive human colon cancer HCT-116 cells, which are an appropriate model to investigate the IR-induced effects (23), and blockade of autophagosomes formation by pharmacological interference. Our finding clearly demonstrate that blockade of IR-induced autophagosomes impairs proliferation but do not enhance cell death in colon cancer cells.

\section{Materials and methods}

Antibodies and reagents. The following antibodies were used in this study: Akt and phospho-Akt antibodies (Cell Signaling Technology, Boston, MA, USA), v-Src and phospho-Src antibodies (Oncogene Research Products, Boston, MA, USA), LC3B antibody (Sigma Chemical Co., St. Louis, MO, USA), $\alpha$-tubulin antibody (Zymed Lab. Inc., San Francisco, CA, USA). The following secondary antibodies were used: Alexa fluor 488-conjugated antibody (Invitrogen Co., Carlsbad, CA, USA) and horseradish peroxidase-conjugated antibody (Sigma Co.) Both 2-(4-Morpholinyl)-8-phenyl-4H-1-benzopyran-4-1 (LY294002) and 1-tert-Butyl-3-(4-chlorophenyl)-1Hpyrazolo(3,4-d)pyrimidin-4-amine (PP2) were purchased from Calbiochem (La Jolla, CA, USA). Annexin V FITC-conjugated and 3-methyladenine (3-MA) were obtained from Sigma Co., and Zymed Lab., respectively.

Cell culture, $\gamma$ irradiation, and pharmacological inhibition. HCT-116 cells (ATCC, number CCL-247, Manassas, VA, USA) were maintained in Dulbelcco's modified Eagle's medium (DMEM) containing 10\% fetal bovine serum (FBS; Gibco) at $37^{\circ} \mathrm{C}$ and $5 \% \mathrm{CO}_{2}$. Irradiation was carried out $48 \mathrm{~h}$ after plating (time 0 ) at $25^{\circ} \mathrm{C}$ using a $137 \mathrm{Cs}$ Irradiator (IBL 437) with a dose of $8.5 \mathrm{~Gy}$ at a dose rate of $2.54 \mathrm{~Gy} / \mathrm{min}$. All analyses were carried out 12, 24, 36, 48 and $72 \mathrm{~h}$ after irradiation.

For pharmacological interference assays, cells were incubated for $60 \mathrm{~min}$ with the kinase inhibitors: $10 \mu \mathrm{M} \mathrm{LY} 294002$
(PI3K) and $170 \mathrm{nM} \mathrm{PP2} \mathrm{(Src).} \mathrm{Cells} \mathrm{were} \mathrm{also} \mathrm{treated} \mathrm{for} 60 \mathrm{~min}$ with $10 \mathrm{mM} 3$-MA, a well-known autophagy inhibitor. Cells were rinsed with phosphate buffered saline (PBS), irradiated as described above, and processed for later analysis.

Annexin V/PI doucble staining. Cells were trypsinized, washed in PBS (pH 7.4), and resuspended in 1X Annexin binding buffer (10 mM HEPES/NaOH, pH 7.4; $140 \mathrm{mM} \mathrm{NaCl}$; $\left.2.5 \mathrm{mM} \mathrm{CaCl}_{2}\right)$. A cell suspension with $10^{5}$ cells $(95 \mu \mathrm{l})$ was then incubated with $5 \mu \mathrm{l}$ of Annexin V-FITC for $60 \mathrm{~min}$ at $4^{\circ} \mathrm{C}$. Prior to flow cytometry analysis, $5 \mu \mathrm{l}$ of a $20 \mu \mathrm{g} / \mathrm{ml}$ propidium iodide stock solution was added to the cells, and then analyzed with a FACScalibur flow cytometer and analyzed in CellQuest software (BD Bioscience, San Jose, CA, USA).

Cell cycle analysis. Cells were harvested by trypsinization and washed once with ice-cold PBS. The cells were then stained in the dark with $75 \mu \mathrm{M}$ propidium iodide and $20 \mu \mathrm{g} / \mathrm{ml}$ RNase A in PBS for at least $30 \mathrm{~min}$ in the presence of NP-40. At least 10,000 events for cell cycle were assessed in these experiments using a FACScalibur flow cytometer and CellQuest software.

Cell proliferation assay. HCT-116 cells (5x10\% $/$ well) were cultured in 96-well plates and after $48 \mathrm{~h}$ of treatment, cell proliferation was assayed in triplicate samples. Cells were fixed in ethanol and stained in a solution of $0.05 \%$ violet crystal in $20 \%$ ethanol. Then, washed, treated in methanol and the optical densities were measured at $595 \mathrm{~nm}$ using a Spectra Max 190 spectrophotometer (Molecular Devices, Sunnyvale, CA, USA).

Supravital cell staining with acridine orange. Cells were cultured on coverslips for $48 \mathrm{~h}$. After irradiation, acridine orange (Sigma) was added at a final concentration of $1 \mu \mathrm{g} / \mathrm{ml}$. Where indicated, Bafilomycin A1 (Sigma), a specific inhibitor of the vacuolar $\mathrm{H}^{+}$-ATPase, was added to the cells at a final concentration of $0.2 \mu \mathrm{M}$ before the addition of acridine orange. The coverslips were washed and mounted using n-propyl gallate. The fluorescence was detected using an Axiovert S 100 microscope equipped with a KS300 image analyzer (Carl Zeiss Inc., Germany).

Immunofluorescence analysis. Cell monolayers were grown on coverslips and subjected to different treatments. Cells were washed, fixed in $4 \%$ freshly prepared formaldehyde, and incubated in $\mathrm{NH}_{4} \mathrm{Cl}$. The cells were then permeabilized with $0.5 \%$ Triton X-100 and blocked with 3\% BSA in PBS. Subsequently, they were incubated with the primary antibody against LC3B $(10 \mu \mathrm{g} / \mathrm{ml})$ followed by incubation with an Alexa fluor 488-conjugated secondary antibody. The coverslips were washed and then mounted using n-propyl gallate. The cell staining was detected using the Axiovert S 100 microscope.

Transmission electron microscopy (TEM). Cells were grown on Transwell polycarbonate filters $(0.4-\mu \mathrm{m}$-pore size; Costar, Cambridge, MA, USA). After IR, cells were fixed in $2.5 \%$ glutaraldehyde, $1 \%$ freshly prepared formaldehyde, $0.8 \%$ sucrose, and $2 \mathrm{mM} \mathrm{CaCl}_{2}$ in $0.1 \mathrm{M}$ cacodylate buffer ( $\mathrm{pH}$ 7.4). Post-fixation was carried out with $1 \%$ osmium tetroxide in cacodylate buffer containing $0.8 \%$ potassium ferrocyanide and $5 \mathrm{mM} \mathrm{CaCl}_{2}$. Subsequently, cells were dehydrated in a graded series of acetone 
A
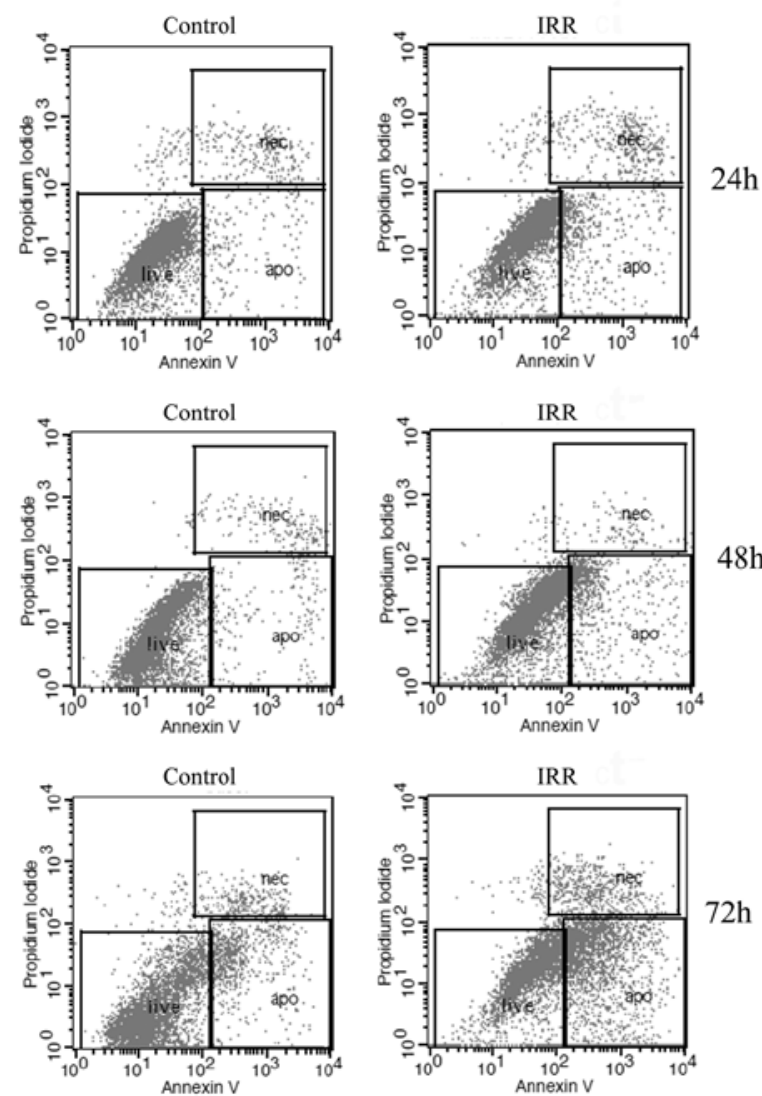

B

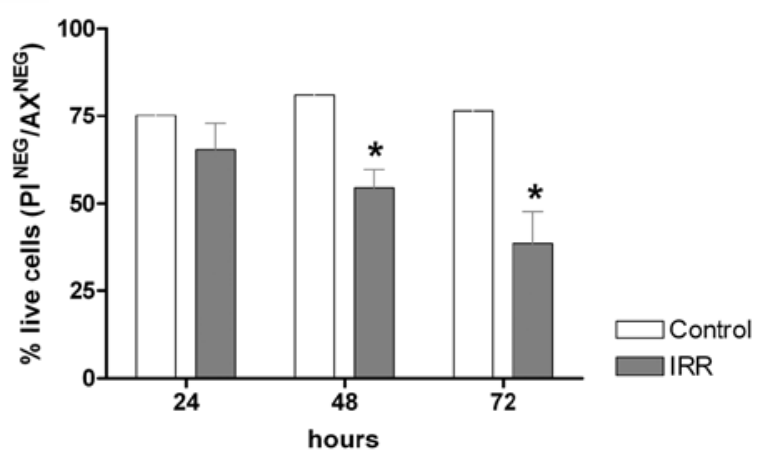

$48 \mathrm{~h}$

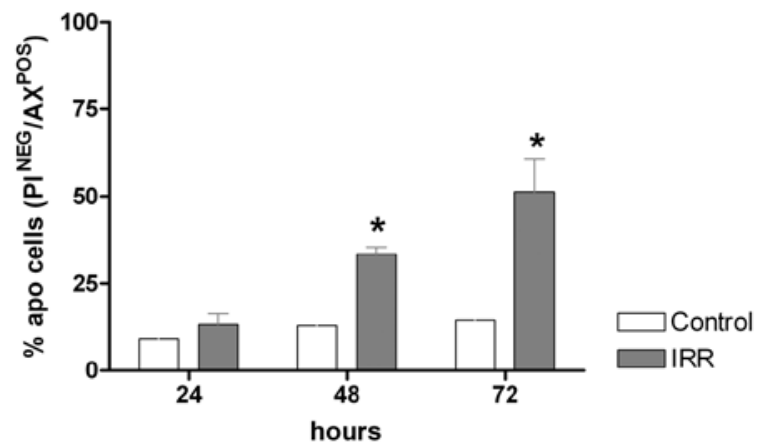

Figure 1. Effect of IR treatment on the cell viability and apoptosis of HCT-116 cells. Cells were grown and irradiated with 8.5 Gy. After 24,48 and $72 \mathrm{~h}$, the cells were subjected to Annexin V/PI staining and analyzed by flow cytometry (A). Quantitative analysis of PI (B) or Annexin V (C) positive cells. Results are representative of three independent experiments. "Significantly different compared to the control group ( $\mathrm{P}<0.05)$.

and embedded in epoxy resin. Ultrathin sections $(60 \mathrm{~nm})$ were stained with uranyl acetate and lead citrate, and examined using a Zeiss CEM-900 transmission electron microscope.

In order to monitor autophagosome formation, cells were grown as described above and incubated for $2 \mathrm{~h}$ at $37^{\circ} \mathrm{C}$ with $10 \mathrm{~nm}$ BSA-Au. Experiments were also carried out in the presence or absence of protein kinase inhibitors to monitor the involvement of cell signaling pathways in organelle formation, and in the presence or absence of 3-MA. After the treatments, cells were washed, irradiated, and incubated for 12,36 or $48 \mathrm{~h}$ at $37^{\circ} \mathrm{C}$. At the indicated time periods, cells were processed for routine electron microscopy as described above. At least 100 cells from each treatment were randomly analyzed.

Western blot analysis. Total lysates were obtained by homogenizing cell samples in RIPA buffer (1\% NP-40; $0.5 \%$ deoxycholate; $0.2 \%$ SDS; $150 \mathrm{mM}$ PBS; and $50 \mathrm{mM}$ Tris-HCl, $\mathrm{pH}$ 7.4) containing $20 \mathrm{mM}$ sodium fluoride, $1 \mathrm{mM}$ sodium orthovanadate, and a cocktail of protease inhibitors (1:100 dilution). Equal amounts of protein samples were separated by SDS-PAGE and transferred to nitrocellulose sheets. The blots were blocked in TBS-T (20 mM Tris-HCl, pH 7.6; $137 \mathrm{mM}$ $\mathrm{NaCl}$; and $0.1 \%$ Tween) containing $1 \% \mathrm{BSA}$, incubated overnight with the indicated antibodies, and then visualized using an enhanced chemiluminiscence (ECL) detection kit (Amersham Biosciences, Buckingham, UK). The protein levels of Akt and
Src with their respective phosphorylated forms were quantified by densitometry using LabWorks 4.6 software (Bio-Rad). In each case, the specific activity score was calculated using the following equation: Arbitrary score $=$ amount of phosphorylated protein/amount of total protein. The protein levels of LC3B were calculated using $\alpha$-tubulin as a loading control. The score for non-irradiated cells was normalized as one in each case.

Statistical analysis. Statistical analysis was performed using two-way ANOVA with a post hoc Bonferroni or Dunnet test in three independent experiments. The significantly different values are indicated in the figure legends as $\mathrm{P}<0.05$ or $\mathrm{P}<0.01$. These values are presented as means \pm standard deviations (SD) from three independent experiments. Significantly different values relative to the control group, and the values relative to irradiated cells are reported.

\section{Results}

Effect of IR treatment on the cell viability and apoptosis of HCT-116 cells. Cells were grown and irradiated with $8.5 \mathrm{~Gy}$. After 24, 48 and $72 \mathrm{~h}$, the cells were subjected to Annexin V/ PI staining and analyzed by flow cytometry (Fig. 1A). We observed that treatment of the HCT-116 cells with 8.5 Gy dose after $24 \mathrm{~h}$ did not affect the cell survival, but after 48 and $72 \mathrm{~h}$ the cell survival was affected in 15 and $40 \%$, respectively, 

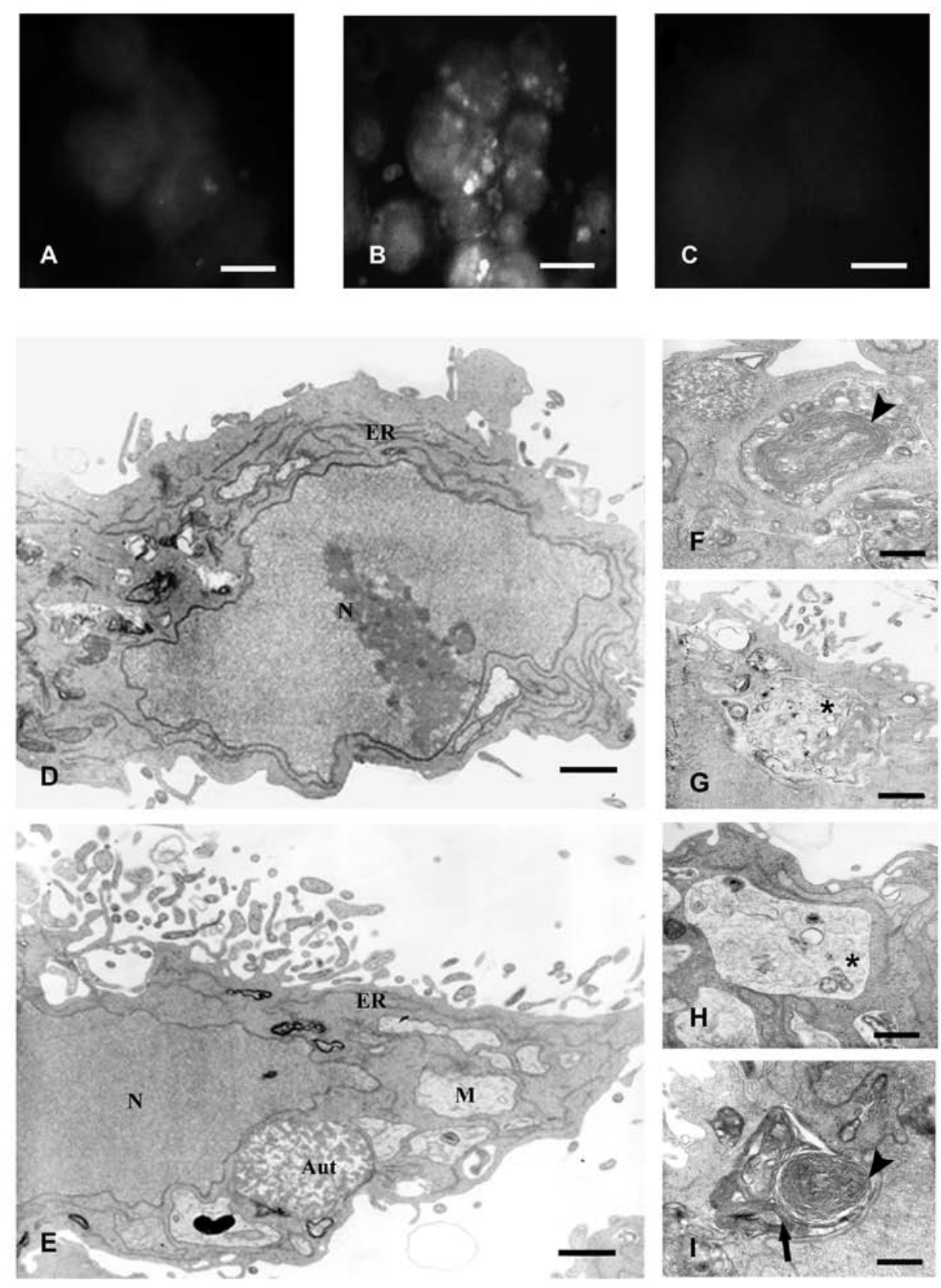

Figure 2. IR promotes acidic vacuole formation that corresponds to autophagosomes. Vital staining with acridine orange of non-irradiated cells (A), $48 \mathrm{~h}$ after irradiation with $8.5 \mathrm{~Gy}$ (B), and incubated with $200 \mathrm{nM}$ Bafilomycin A1 for $30 \mathrm{~min}$ before the addition of acridine orange (C). Bar, $10 \mu \mathrm{m}$. (D and E) Representative electron microscopy micrographs of non-irradiated and irradiated cells with $8.5 \mathrm{~Gy}$ after $48 \mathrm{~h}$, respectively. The nuclei of irradiated cells exhibited a similar ultrastructure as that observed in control cells and did not show morphological characteristics of apoptosis, such as chromatin margination or nuclear pyknosis. At a higher magnification, it was observed that most of the autophagic vacuoles arise from newly formed lamellar structures (arrowhead) (F) and double-membrane autophagosomes that sequester organelles (arrow) (I) to single-membrane organelles that contain digested material (asterisks) (G and H). (D and E) Bars, $0.2 \mu \mathrm{m}$. (F-I) Bars, $0.3 \mu \mathrm{m}$. N, nuclei; ER, endoplasmic reticulum; M, mitochondria; and Aut, autophagolysosomes.

as compared to untreated cells (Fig. 1B). We further examined if IR was able to induce cell death by apoptosis using flow cytometry analysis of cells stained with Annexin V/ PI. We observed that IR after $24 \mathrm{~h}$ did not alter the levels of apoptotic cells as compared with untreated cells, but after 48 and $72 \mathrm{~h}$ a rate of 15 and $60 \%$ of apoptotic cells was observed, respectively (Fig. 1C). Based on these results, we used the time of $48 \mathrm{~h}$ after IR as treatment condition for all subsequent studies.

IR promotes acidic vacuole formation that corresponds to autophagosomes. We observed that a major population of cell survived to IR after $48 \mathrm{~h}$, while a minor amount was induced to die. Thus, we decided to analyze other events in programmed cell death, such as the additional type II of programmed death or autophagy, which is characterized by the presence of acidic vacuole formation (20). These vacuoles are characterized by labeling with acridine orange, widely known to accumulate in acidic compartments. The majority of untreated cells had only a few labeled vesicles (Fig. 2A); in contrast irradiated cells at $48 \mathrm{~h}$ had large fluorescent vacuoles in the cytoplasm (Fig. 2B). We confirm the acidic nature of the vacuoles by incubating the cells with Bafilomicyn A1, a well-known inhibitor of the vacuolar $\mathrm{H}^{+}$-ATPase responsible for preventing the proper acidification of 
A
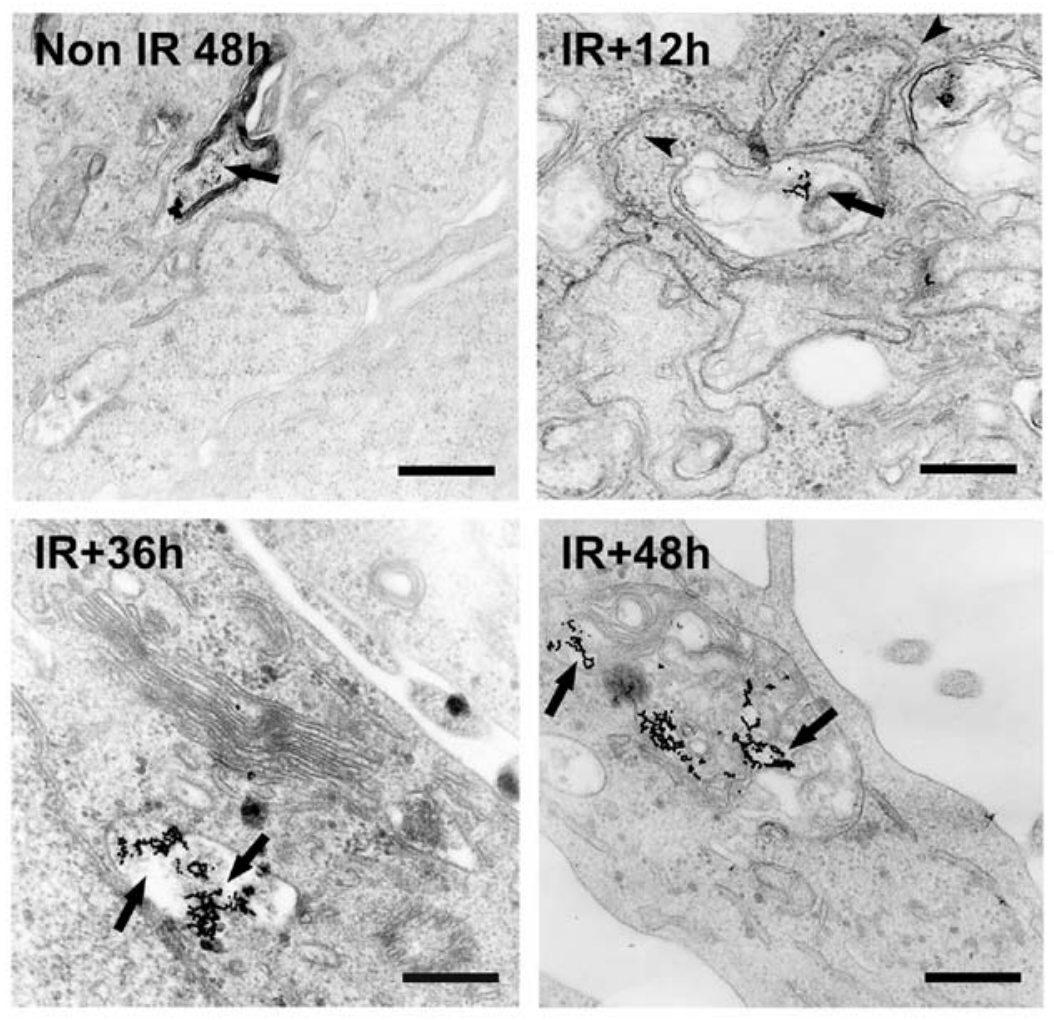

B
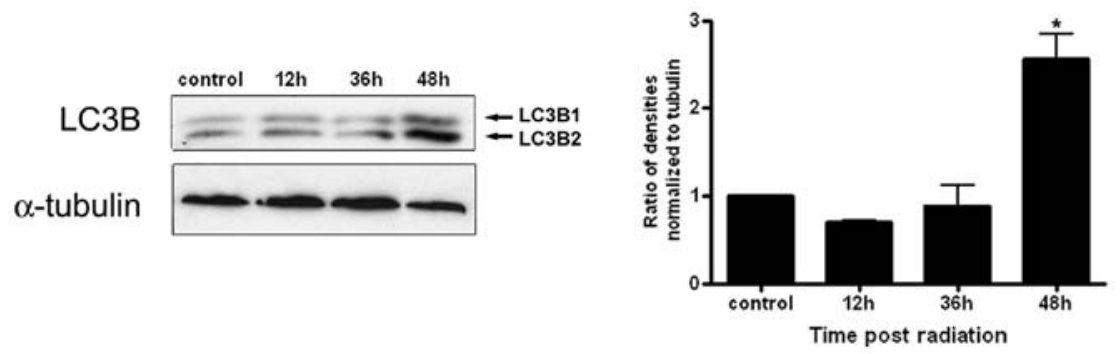

Figure 3. Biogenesis of autophagosomes induced after irradiation. (A) Representative electron micrographs showing a kinetic analysis of the autophagolysosome biogenesis. Cells were first incubated with BSA-Au for $2 \mathrm{~h}$ and some cells were irradiated with 8 Gy; all cells were then analyzed by electron microscopy. Control cells had labeling at lysosome-like structures after $48 \mathrm{~h}$ of incubation. After $12 \mathrm{~h}$ of irradiation, the labeling was present in organelles surrounded by double membranes (arrowheads). Labeling was observed in the autophagosome-like structures after $36 \mathrm{~h}$ and within $48 \mathrm{~h}$ in mature autophagosomes or autophagolysosomes (arrows represent the BSA-Au marker; bars, $0.3 \mu \mathrm{m}$ ). (B) Western blot analysis of LC3B in control cells and cells irradiated with $8 \mathrm{~Gy}$ after 12,26 and $48 \mathrm{~h}$. Irradiated cells after $48 \mathrm{~h}$ displayed a significant increase in both isoforms but primarily in LC3BII. $\alpha$-tubulin was used as a loading control. Results are representative of three independent experiments. *Significantly different compared to the control group $(\mathrm{P}<0.05)$.

lysosomal compartments (24). In the presence of the inhibitor, no acridine orange-labeled vacuoles were observed in irradiated cells (Fig. 2C).

Further analysis by TEM showed that the IR-induced acidic vacuoles corresponded to large vacuoles containing electron dense material but the nuclei and organelles had typical morphology similar to control cells and did not show morphological characteristics of apoptosis, such as chromatin margination or nuclear pyknosis (Fig. 2D and E). Forty-eight hours after IR, accumulation of these organelles was observed in $\sim 80 \%$ of the analyzed cells, which displayed a core composed of granular, vesicular, or lamellar contents. Furthermore, the organelles were frequently surrounded by smooth and/or rough membrane cisternae or in fusion with smooth vesicles of unknown origin (Fig. 2F-I). Early studies have characterized the integration of the endocytic and autophagic pathways using BSA-Au as a marker of fluid-phase endocytosis (25). Using this approach, we observed the labeling with the marker of lysosome-like organelles in unirradiated cells after $48 \mathrm{~h}$. In irradiated cells the marker was observed in double membranes in apparent sequestration of organelles (12 h), initial autophagosomes contained non-degraded material, indicating that the absence of lysosomal hydrolases $(36 \mathrm{~h})$, and in single membrane-bound autophagosomes containing multivesicular material (48 h) (Fig. 3A).

We confirmed these results by Western blot analysis using anti-LC3B, an antibody that recognizes two forms of LC3B (LC3B-I and LC3-II). In Fig. 3B, we show a significant increase in LC3B-II levels $48 \mathrm{~h}$ after IR treatment. The increased LC3B-II level is associated with increased autophagosome membranes and correlates with the extent of autophagosomes formation (26). 

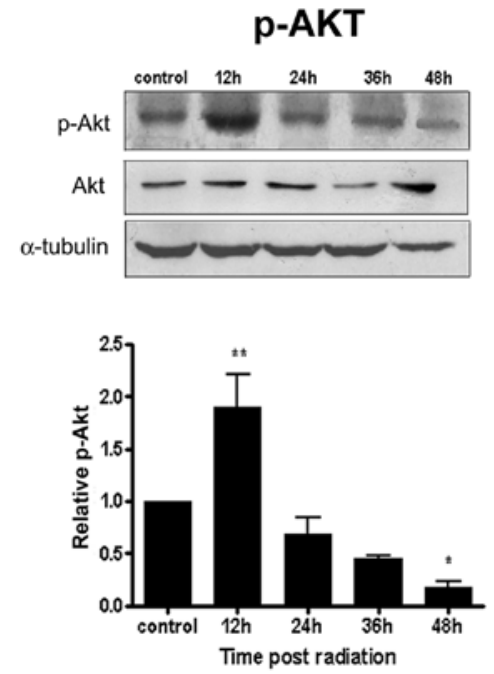
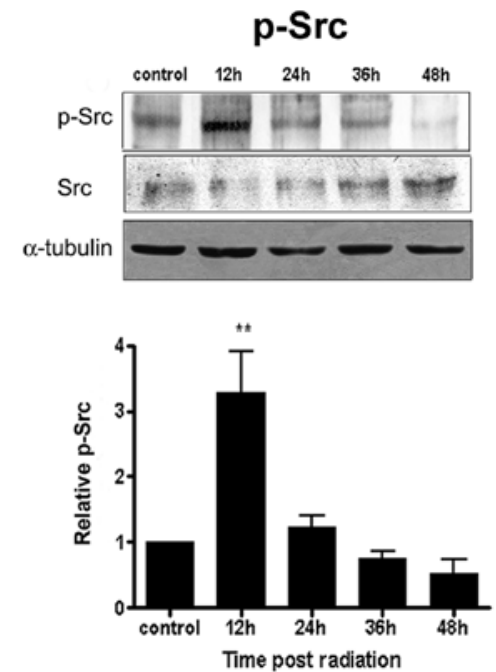

Figure 4. IR induces activation of PI3K/Akt and Src protein kinases. HCT-116 cells were irradiated with 8.5 Gy. Cell extracts were obtained at the indicated times and analyzed for total Akt and Src and their respective phosphorylated forms by Western blotting. A significant increase in the activity of the two kinases after $12 \mathrm{~h}$ of irradiation is shown with a progressive decline in their phosphorylation status. $\alpha$-tubulin was used as a loading control. Results are representative of three independent experiments. " Significantly different compared to the control group $\left({ }^{*} \mathrm{P}<0.05\right) ;\left({ }^{* * *} \mathrm{P}<0.01\right)$.

A
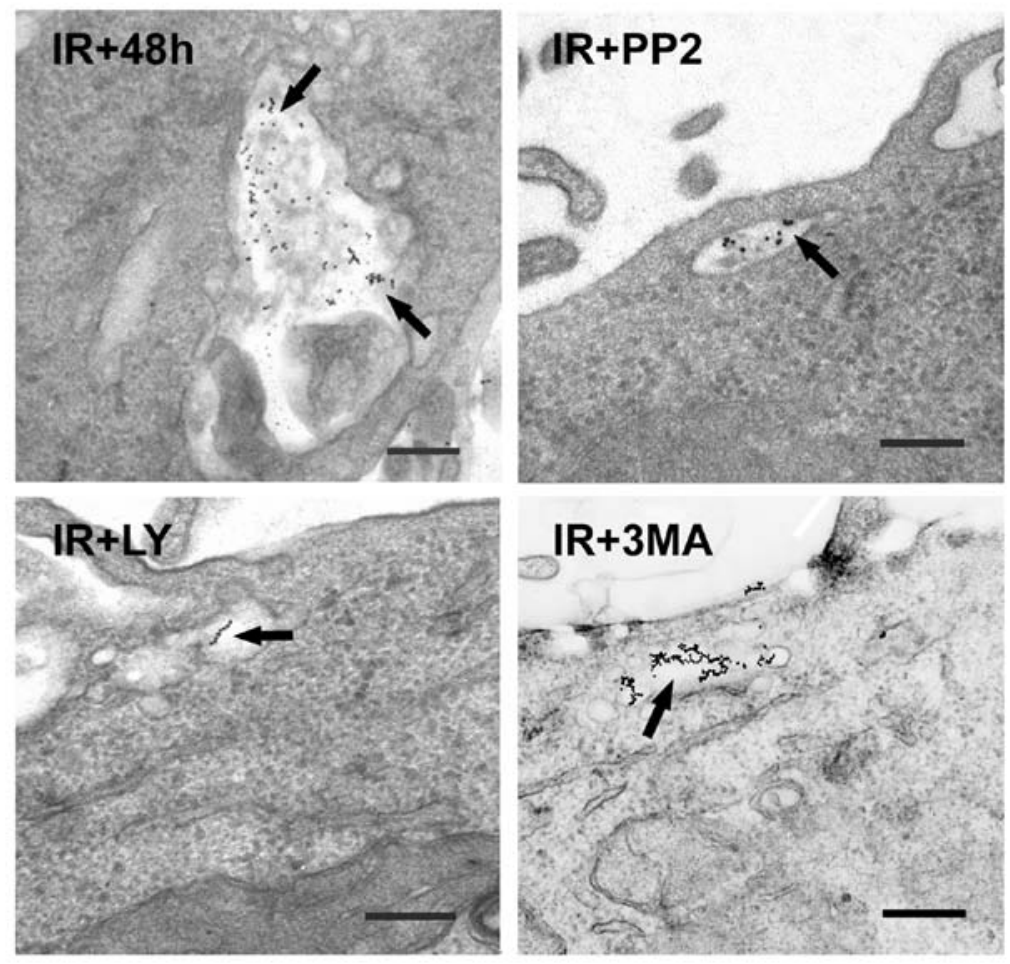

B

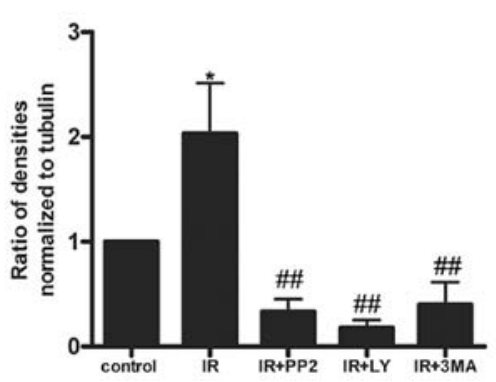

Figure 5. Autophagosome biogenesis is dependent on PI3k/Akt and Src activation in the early stages of irradiation. HCT-116 cells were grown, pretreated with LY294002 and PP2 or with 3-methyladenine for $1 \mathrm{~h}$, and irradiated with $8.5 \mathrm{~Gy}$. After $48 \mathrm{~h}$, the formation of autophagolysosomes was examined by electron microscopy using the BSA-Au marker or by Western blotting with LC3B antibody. (A) An intense BSA-Au labeling inside autophagosomes in irradiated cells and labeled organelles was only observed in early endosomes in the presence of the inhibitors (bar, $0.3 \mu \mathrm{m}$ ). (B) Concomitantly, a significant decrease in the autophagosome marker LC3B was observed after pretreatment with the inhibitors. "Significantly different compared to the control group ("P<0.05). 

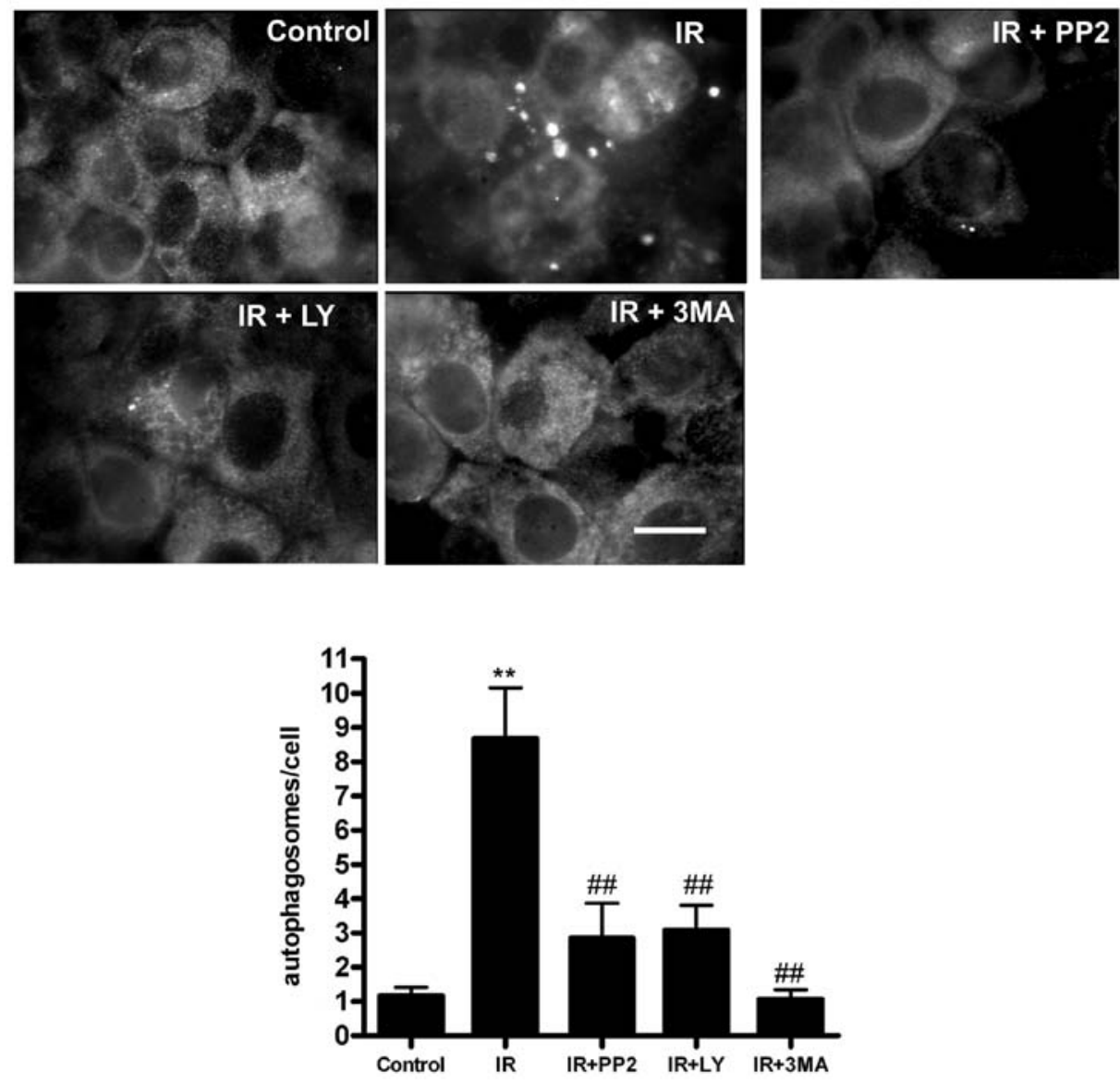

Figure 6. Quantitative immunofluorescence analysis of irradiation-induced autophagosome formation and blockade by inhibitor treatments. HCT-116 cells were grown, pretreated with LY294002 and PP2 or with 3-methyladenine for $1 \mathrm{~h}$, and irradiated with $8.5 \mathrm{~Gy}$. After $48 \mathrm{~h}$, the formation of autophagososomes was analyzed by immunofluorescence using LC3B antibody. The following features were observed: little or no staining in control cells, intense labeling in irradiated cells in the absence of inhibitors, and the disappearance of staining in cells pretreated with inhibitors. Bars, $4 \mu \mathrm{m}$. ${ }^{* *}$ Significantly different compared to the control group ( $\mathrm{P}<0.01)$.

Irradiation induces PI3K/Akt and Src activation concomitantly with autophagosome formation at early stages after irradiation . To identify cell signaling pathways involved in the formation of autophagosomes, we first analyzed by Western blotting the phosphorylation status of Akt, a downstream target of PI3K, and of Src after irradiation. We observed a significant increase in the phosphorylation levels of these kinases $12 \mathrm{~h}$ after IR. At subsequent post-IR times, the phosphorylation of the kinases decreased when compared to control cells (Fig. 4). These data implicate the involvement of PI3K/Akt and Src activation at the initial stages of autophagosome formation, where organelle sequestration and the initial formation of autophagosomes occur.

We monitored the autophagosome formation in response to PI3K and Src inhibition using the specific inhibitors, LY294002 and PP2, respectively, and 3-MA as a control for autophagy inhibition. TEM analysis showed that $\sim 80 \%$ of the irradiated cells displayed a strong BSA-Au labeling into the autophagosomes, and the treatment with the inhibitors caused a blockade of autophagosome formation. Irradiated cells treated with the inhibitors only had organelles resembling early and late endosomes labeled with the marker (Fig. 5A). We further confirmed that the autophagosome formation depends on the early activation of PI3K/Akt and Src by Western blotting using LC3B. Fig. 5B shows that pretreatment with the inhibitors significantly inhibited the expression of LC3B in response to IR. Next, quantitative immunofluorescence using the LC3B marker demonstrated that pretreatment with the inhibitors significantly inhibited autophagosome formation (Fig. 6). Together, these data indicate that the activation of PI3K/Akt and Src during the early stages of irradiation (12 h) is necessary to induce a cell signaling cascade that leads to autophagosome formation in HCT-116 cells.

Blockade of IR-induced autophagosome formation by PI3K/ Akt and Src inhibition impairs proliferation but does not enhance cell death. Various studies suggest that the autophagic response of cancer cells to radiotherapy is a major pathway that may lead to cell death or survival in contrast to apoptosis, which only leads to cell death (27). Autophagy is a temporary survival mechanism under stress conditions, but its inhibition may either promote or inhibit cell death depending on the conditions and agents used $(7,28)$. Thus, we decided to analyze cell proliferation measuring crystal violet incorporation, which correlates with the total cell number, after the blockade of autophagosome formation with PI3K/Akt, Src, and 3-MA. Fig. 7A shows that IR caused a decrease in proliferation after $48 \mathrm{~h}$ when compared to non-irradiated cells, and that the pretreatment with the inhibitors significantly decreased proliferation relative to cells treated with IR alone. This suggests that the blockade of IR-induced autophagosomes causes a synergistic inhibitory effect on the total number of irradiated cells at the time of $48 \mathrm{~h}$. 
A
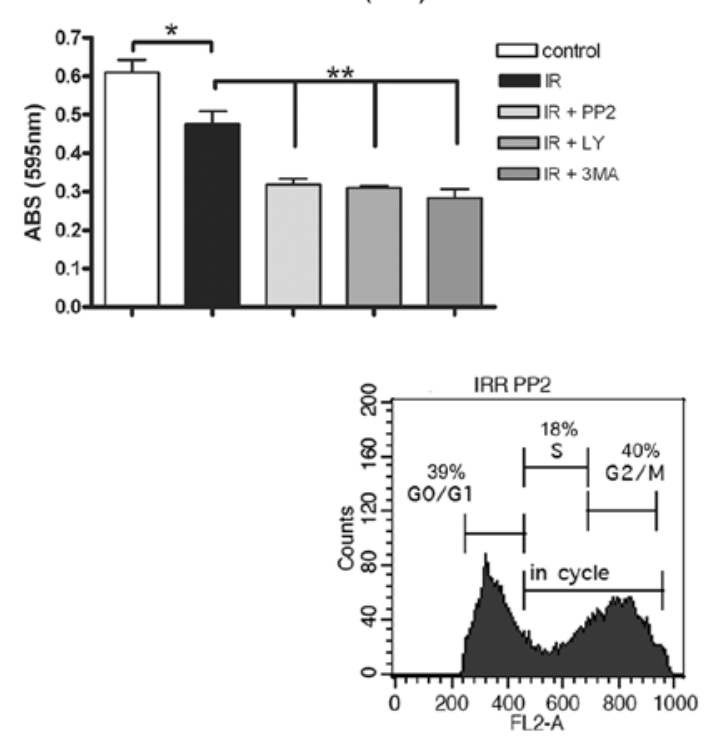

B
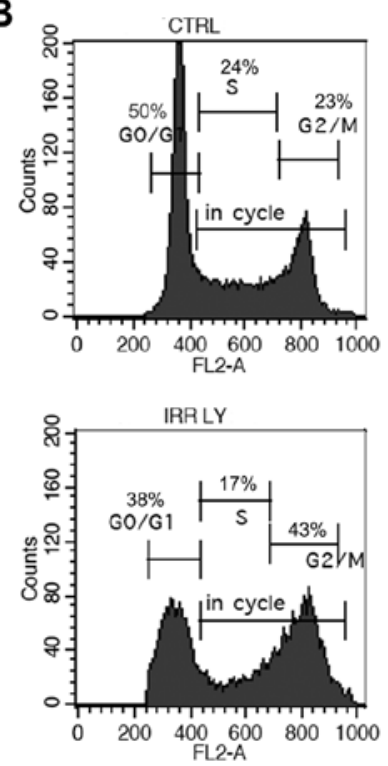
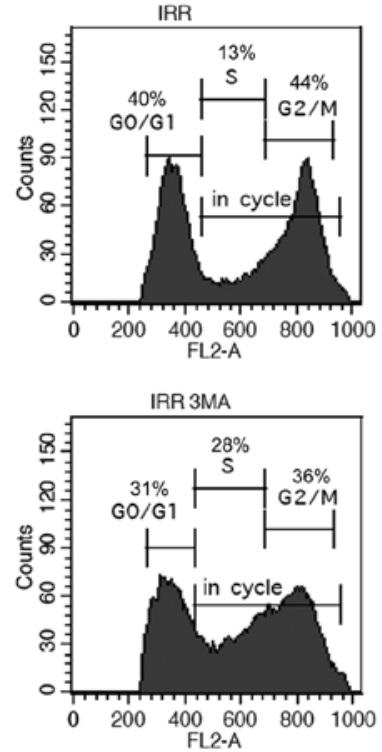

Figure 7. Blockade of IR-induced autophagosome formation by PI3K/Akt and Src inhibition impairs proliferation but do not enhance cell death. HCT-116 cells were grown, pretreated with LY294002 and PP2 or with 3-methyladenine for $1 \mathrm{~h}$, and irradiated with 8.5 Gy. After 48 h, the proliferation (A) and cell cycle analysis (B) were analyzed as described in Materials and methods. Observe that the blockade of IR-induced autophagosomes causes an inhibitory synergistic

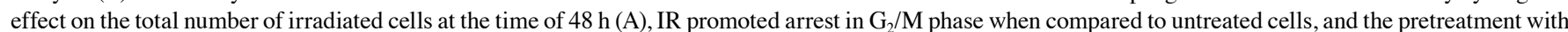
kinase inhibitors and 3MA prior to IR increased the amount of cells in S phase as compared with irradiated cells (B). Data represent the mean \pm SD from three independent experiments. "Significantly different compared to the control group $\left({ }^{*} \mathrm{P}<0.05\right)$.

In order to determine whether the inhibition of HCT-116 cell growth caused by the blockade of IR-induced autophagosome formation was due to alteration of the cell cycle, we investigated the cycle profiles analyzing the DNA content by flow cytometry. As shown in Fig. 7B, the phases of cell cycle distribution indicated that IR promoted arrest in $G_{2} / M$ phase at $48 \mathrm{~h}$, as compared to untreated cells. Pretreatment with kinase inhibitors and 3-MA increased the amount of cells in S phase as compared with irradiated cells. The percentage of pretreated cells in the Sub- $\mathrm{G}_{0}$ phase was very similar to those irradiated only (data not shown). At $72 \mathrm{~h}$, the population of cells pretreated with the inhibitors in $\mathrm{G}_{2} / \mathrm{M}$ phase was similar to those irradiated only (data not shown). Taken together, these results suggest that the growth-inhibitory effect as consequence of the blockade of autophagosomes formation could be partly due to its ability to retard $\mathrm{S}$ phase of the cell cycle rather than leading cells to apoptosis-mediated death. To investigate in more detail the role of autophagy on the inhibitory effect of proliferation, we examined whether the autophagy inhibitors could attenuate cell survival. We observed that pretreatment with the inhibitors did not alter cell viability (Fig. 8A) or the cell death by apoptosis (Fig. 8B) in relation to those resulting from $48 \mathrm{~h}$ after IR. Together, these results indicate that autophagy inhibition decreases cell proliferation but did not enhance the IR-mediated cell death. Additionally, an accentuated effect on these two parameters was observed after $72 \mathrm{~h}$, however none of the inhibitors altered the effects on cell death after IR (data not shown).

\section{Discussion}

Colorectal cancer is the second most prevalent cancer and the third leading cause of cancer deaths worldwide, and radio-
A

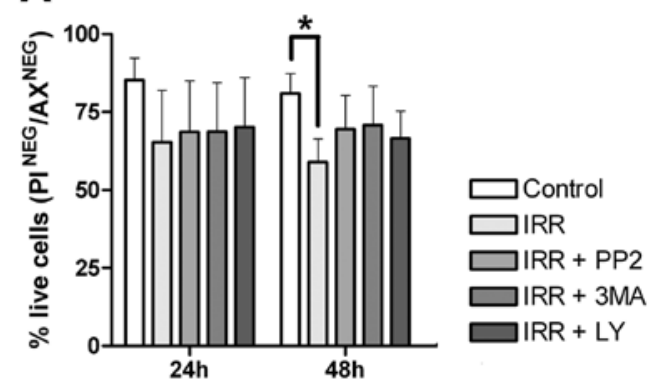

B

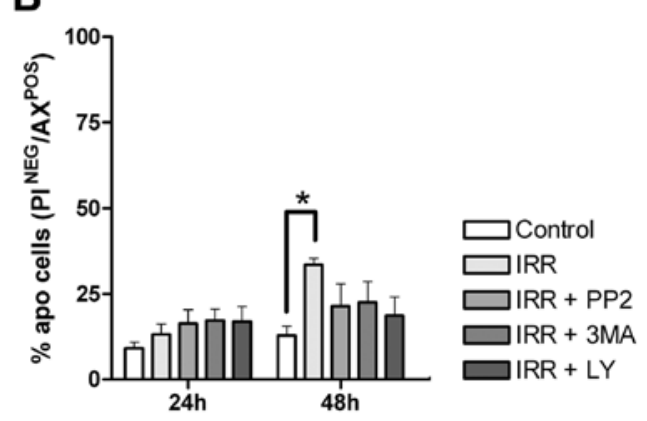

Figure 8. Pretreatment with the inhibitors did not alter the cell viability or the cell death by apoptosis in relation to observed after irradiation. Cells were grown and irradiated with $8.5 \mathrm{~Gy}$. After 24 and $48 \mathrm{~h}$ cells were subjected to Annexin V/PI staining and analyzed by flow cytometry. Quantitative analysis of the percentage of PI-(A) or Annexin V-(B) positive cells. Results are representative of three independent experiments. *Significantly different compared to the control group $\left({ }^{*} \mathrm{P}<0.05\right)$.

therapy remains the major adjuvant therapy to improve survival rates and reduce the risk of local recurrence (29). However, this therapy may contribute to cellular responses related to neoplastic 
progression. One of these responses involve autophagosome formation as a cell defense mechanism (30), but the precise molecular mechanisms underlying formation of these organelles and its relation with tumor cell survival in response to radiation remain to be defined.

To further address this issue, we initially analyzed whether IR impairs cell viability or induces apoptosis in HCT-116 cells. We observed that IR induced approximately $15 \%$ of cell death by apoptosis after $48 \mathrm{~h}$ of treatment, but $75 \%$ of cells survived this treatment. These findings corroborate previous studies showing that irradiated cells develop an adaptive response as a self-defense mechanism that protects cells rather than causing cell death (31). It was shown that depletion or inhibition of p53 could induce autophagy suggesting a key role for the p53 tumor suppressor in the regulation of autophagy (32). However, recently using both WT and p53-null HCT-116 cells that were treated with the cell wall skeleton of Mycobacterium bovis Bacillus Calmette-Guerin (BCG/CWS) plus IR, it was shown that p53 was not involved in autophagy induction (33). Therefore, these findings also indicate that autophagy and apoptosis use different mechanisms of control.

Various studies have suggested that anticancer therapies, such as hormonal agents, chemotherapy and IR, frequently induce autophagy, in most cases as a pro-survival response potentially contributing to treatment resistance $(34,35)$. Thus, we evaluated autophagosome formation, which is the most distinctive feature of autophagy. Our results showed that IR induced the accumulation of large vacuoles derived from the autophagic pathway, as characterized by the following parameters: a) acidic nature, b) enclosure by a double membrane, c) presence of degraded material derived from organelles such as the endoplasmic reticulum or mitochondria in their lumen, and d) labeling with LC3B (Figs. 2 and 3). As previously reported, these criteria are well-known characteristics of autophagosome formation (36).

Previous morphological studies have shown a link between the endocytic and autophagic pathways (37); therefore we used the convergence of these pathways to monitor the formation of IR-induced autophagosomes using BSA-Au, a classic fluid-phase endocytosis marker, and TEM analysis (25). Using this approach we showed that IR induced the formation of autophagosomes after $48 \mathrm{~h}$ (Fig. 3A), which was confirmed by measuring LC3 expression levels by Western blotting (Fig. 3B). There are no previous reports demonstrating the biogenesis of IR-induced autophagosomes in invasive colon cancer cells. The present study reinforces a previous report suggesting that the integration of autophagic vacuoles with vacuoles of the endocytic pathway is a prerequisite of autophagosome maturation (1), and provide a valuable model to investigate molecular mechanisms that control autophagosome biogenesis.

Autophagy is a dynamic process regulated by several cell signaling pathways $(5,38)$, however, the molecular control of IR-induced autophagy, particularly in colon cancer cells, remains poorly understood. In human breast tumor cells, a link between autophagic responses to IR and mTOR signaling was reported (31. It was shown that clinically relevant IR doses increased the phosphorylated forms of mTOR, Akt, and S6 ribosomal proteins (39). Therefore, inhibitors of the PI3K/Akt/mTOR pathway have emerged as important and attractive therapeutic strategies for cancer therapy. Our results demonstrated that PI3K/Akt and Src signaling were involved in autophagy control (Figs. 4-6). We suggest that IR, known to activate growth-factor receptors $(40,41)$, could increase the activity of Ras family oncoproteins causing subsequent activation of downstream effectors such as PI3K/Akt and Src, which in turn, may modulate autophagosome formation. Once these IR-activated signaling pathways are correlated with cell survival, we can also speculate that IR-induced autophagy in this cell type is an attempt to avoid apoptosis in response to this treatment. It is important to point out that LY294002 is a known inhibitor of autophagy as well as of PI3K signaling (42) and suppresses the activity of the downstream Akt. However, this inhibitor also induces rather than inhibits autophagy in malignant glioma cells. One explication to this controversy could be that the effects of LY294002 on autophagy depend on the cell type or treatment conditions, such as concentration used and exposure time, which can affect the mTOR pathway (43).

We further analyzed cell proliferation and survival rates to investigate if the blockade of autophagy could be sufficient to enhance cell death induced by IR. Interestingly, the concentration of inhibitors that induced autophagy blockade did not increase apoptotic cell death but significantly inhibited the proliferation of irradiated cells (Figs. 7 and 8). This latter observation could indicate that the decreased proliferation induced by the blockade of autophagy was due to a delay of the cell cycle in $\mathrm{S}$ phase. To confirm this hypothesis we analyzed the cell cycle progression $72 \mathrm{~h}$ after IR, and observed a restoration of the cell population in $\mathrm{G}_{2} / \mathrm{M}$ in the group treated with kinase inhibitors as compared with the irradiated group only. This suggests that the presence of autophagosomes is important to progress the cell cycle from $S$ to $G_{2} / M$ where $G_{2}$ checkpoint allows the cell to repair the DNA damage after IR. Recently, it was shown that IR-induced autophagy promotes post-IR cell survival and contributes to cellular radioresistance in breast cancer cell lines (44); however experimental evidence to explain this conclusion was not explored. Of note, the PI3K/Akt pathway is a survival pathway that via its inhibition does not always cause substantial apoptosis, therefore, additional treatment with other agents is necessary to cause abnormal autophagosome accumulation and leads to accelerated cell death (45).

In conclusion, we showed that IR-induced autophagy is a initial mechanism of tumor cell survival, and that autophagy inhibition induces a delay of the cell cycle in $\mathrm{S}$ phase rather than leading cells to apoptosis-mediated death. Therefore, cell death in response to autophagy inhibition may vary among each type of cancer due to the different biological characteristics and therapeutic treatments, as previously reported (46). In the future, the understanding of the molecular mechanisms underlying IR-induced autophagy as well as the combination with other drugs that interfere with other defense programs may increase the efficacy in radiation oncology.

\section{Acknowledgements}

This study was sponsored by Conselho Nacional de Desenvolvimento Cientifico e Tecnologico (CNPq), Ministério da Saúde, Brasil, and Fundação Carlos Chagas Filho de Amparo à Pesquisa do Estado de Rio de Janeiro (FAPERJ). We are grateful to Barbara DuRocher for her valuable help in the interpretation of the cell cycle experiments, Livia Goto-Silva for suggestions made at the beginning of the present study, the Programa de Cooperação INCA/FIOCRUZ for the use of their facility and 
the employers of Departamento de Hemoterapia-INCA for the use of gamma irradiator.

\section{References}

1. Razi M, Chan EY and Tooze SA: Early endosomes and endosomal coatomer are required for autophagy. J Cell Biol 185: 305-321, 2009.

2. Levine B and Klionsky DJ: Development by self-digestion: molecular mechanisms and biological functions of autophagy. Dev Cell 6: 463-477, 2004.

3. Meijer AJ and Codogno P: Regulation and role of autophagy in mammalian cells. Int J Biochem Cell Biol 36: 2445-2462, 2004.

4. Ogier-Denis E and Codogno P: Autophagy: a barrier or an adaptive response to cancer. Biochim Biophys Acta 1603: 113-128, 2003.

5. Rubinsztein DC, Gestwicki JE, Murphy LO and Klionsky DJ: Potential therapeutic applications of autophagy. Nat Rev Drug Discov 6: 304-312, 2007.

6. Apel A, Herr I, Schwarz H, Rodemann HP and Mayer A: Blocked autophagy sensitizes resistant carcinoma cells to radiation therapy. Cancer Res 68: 1485-1494, 2008.

7. Amaravadi RK, Yu D, Lum JJ, et al: Autophagy inhibition enhances therapy-induced apoptosis in a Myc-induced model of lymphoma. J Clin Invest 117: 326-336, 2007.

8. Bursch W, Ellinger A, Kienzl H, et al: Active cell death induced by the anti-estrogens tamoxifen and ICI 164384 in human mammary carcinoma cells (MCF-7) in culture: the role of autophagy. Carcinogenesis 17: 1595-1607, 1996.

9. Kondo Y, Kanzawa T, Sawaya R and Kondo S: The role of autophagy in cancer development and response to therapy. Nat Rev Cancer 5: 726-734, 2005.

10. Yue Z, Jin S, Yang C, Levine AJ and Heintz N: Beclin 1, an autophagy gene essential for early embryonic development, is a haploinsufficient tumor suppressor. Proc Natl Acad Sci USA 100: 15077-15082, 2003.

11. Qu X, Yu J, Bhagat G, et al: Promotion of tumorigenesis by heterozygous disruption of the Beclin 1 autophagy gene. J Clin Invest 112: 1809-1820, 2003.

12. Aita VM, Liang XH, Murty VV, et al: Cloning and genomic organization of Beclin 1, a candidate tumor suppressor gene on chromosome 17q21. Genomics 59: 59-65, 1999.

13 Crighton D, Wilkinson S, O'Prey J, et al: DRAM, a p53-induced modulator of autophagy, is critical for apoptosis. Cell 126 $121-134,2006$.

14. Corcelle E, Nebout M, Bekri S, et al: Disruption of autophagy at the maturation step by the carcinogen lindane is associated with the sustained mitogen-activated protein kinase/extracellular signal-regulated kinase activity. Cancer Res 66: 6861-6870, 2006

15. Klionsky DJ and Erm SD: Autophagy as a regulated pathway of cellular degradation. Science 290: 1717-172, 2000.

16. Chen S, Rehman SK, Zhang W, Wen A, Yao L and Zhang J: Autophagy is a therapeutic target in anticancer drug resistance. Biochim Biophys Acta 1806: 220-229, 2010.

17. Furuta S, Hidaka E, Ogata A, Yokota S and Kamata T: RAS is involved in the negative control of autophagy through the class IP3-kinase. Oncogene 23: 3898-3904, 2004.

18. Arico S, Petiot A, Bauvy C, et al: The tumor suppressor PTEN positively regulates macroautophagy by inhibiting the phosphatidylinositol 3-kinase/protein kinase B pathway. J Biol Chem 276: 35243-35246, 2001.

19. Ogier-Denis E, Pattingre S, Benna $J$ and Codogno P: Erk1/2dependent phosphorylation of Galpha-interacting protein stimulates its GTPase accelerating activity and autophagy in human colon cancer cells. J Biol Chem 275: 39090-39095, 2000.

20. Paglin S, Hollister T, Delohery T, et al: A novel response of cancer cells to radiation involves autophagy and formation of acidic vesicles. Cancer Res 61: 439-444, 2001.

21. Brown M and Wounters BG: Apoptosis, p53, and tumor cell sensitivity to anticancer agents. Cancer Res 59: 1391-1399, 1999.

22. Finkel E: Does cancer therapy trigger cell suicide? Science 286: 2256-2258, 1999.

23. Speake WJ, Dean RA, Kumar A, Morris TM, Scholefield SA and Watson JH: Radiation induced MMP expression from rectal cancer is short lived but contributes to in vitro invasion. Eur J Surg Oncol 31: 869-871, 2005.
24. Yamamoto A, Tagawa Y, Yoshimori T, Moriyama Y, Masaki R and Tashiro Y: Bafilomycin A1 prevents maturation of autophagic vacuoles by inhibiting fusion between autophagosomes and lysosomes in rat hepatoma cell line, H-4-II-E cells. Cell Struct Funct 23: 33-42, 1998.

25. Fengsrud M, Roos N, Berg T, Liou W, Slot JW and Seglen PO: Ultrastructural and immunocytochemical characterization of autophagic vacuoles in isolated hepatocytes: effects of vinblastine and asparagine on vacuole distributions. Exp Cell Res 221: 504-519, 1995.

26. Kabeya Y, Mizushima N, Ueno T, et al: LC3, a mammalian homologue of yeast Apg8p, is localized in autophagosome membranes after processing. EMBO J 19: 5720-5728, 2003.

27. Zois CE and Koukourakis MI: Radiation-induced autophagy in normal and cancer cells: towards novel cytoprotection and radiosensitization policies? Autophagy 5: 442-450, 2009.

28. Levine B and Yuan J: Autophagy in cell death: an innocent convict? J Clin Invest 115: 2679-2688, 2005.

29. Li J, Hou N, Faried A, Tsutsumi S and Kuwano H: Inhibition of autophagy augments 5-fluorouracil chemotherapy in human colon cancer in vitro and in vivo model. Eur J Cancer 46: 1900-1909, 2010

30. Kondo Y and Kondo S: Autophagy and cancer therapy. Autophagy 2: 85-90, 2006.

31. Paglin S, Lee NY, Nakar C, et al: Rapamycin-sensitive pathway regulates mitochondrial membrane potential, autophagy, and survival in irradiated MCF-7 cells. Cancer Res 65: 11061-110702, 2005.

32. Tasdemir E, Maiuri MC, Galluzzi L, et al: Regulation of autophagy by cytoplasmic p53. Nat Cell Biol 10: 676-687, 2008.

33. Yuk JM, Shin DM, Song KS, et al: Lim K, Kim KH, Lee SH, Kim JM, Lee JS, Paik TH, Kim JS and Jo EK: Bacillus calmetteguerin cell wall cytoskeleton enhances colon cancer radiosensitivity through autophagy. Autophagy 6: 46-60, 2010.

34. Al-Ejeh F, Kumar R, Wiegmans A, Lakhani SR, Brown MP and Khanna KK: Harnessing the complexity of DNA damage response pathways to improve cancer treatment outcomes. Oncogene 29: 6085-6098, 2010.

35. John S, Nayvelt I, Hsu HC, Yang P, Liu W and Das GM: Regulation of estrogenic effects by beclin 1 in breast cancer cells. Cancer Res 68: 7855-7863, 2008

36. Eskelinen EL: Maturation of autophagic vacuoles in mammalian cells. Autophagy 1: 1-10, 2005.

37. Hamasaki M and Yoshimori T: Where do they come from? Insights into autophagosome formation. FEBS Lett 584: 1296-1301, 2010.

38. Corcelle EA, Puustinen $P$ and Jäättlelä $M$ : Apoptosis and autophagy: targeting autophagy signaling in cancer cells - 'trick or treats'? FEBS J 276: 6084-6096, 2009.

39. Albert JM, Cao KW and Lu B: Targeting the Akt/mammalian target of rapamycin pathway for radiosensitization of breast cancer. Mol Cancer Ther 5: 1183-1189, 2006.

40. Dent P, Reardon DB, Park JS, et al: Radiation-induced release of transforming growth factor alpha activates the epidermal growth factor receptor and mitogen-activated protein kinase pathway in carcinoma cells, leading to increased proliferation and protection from radiation-induced cell death. Mol Biol Cell 10: 2493-2506, 1999.

41. Goldkorn T, Balaban N, Shannon M and Matsukuma K: EGF receptor phosphorylation is affected by ionizing radiation. Biochim Biophys Acta 1358: 289-299, 1997.

42. Aki T, Yamaguchi K, Fujimiya T and Mizukami Y: Phosphoinositide 3-kinase accelerates autophagic cell death during glucose deprivation in the rat cardiomyocyte-derived cell line $\mathrm{H} 9 \mathrm{c} 2$. Oncogene 22: 8529-8535, 2003.

43. Takeuchi H, Kondo Y, Fujiwara K, et al: Synergistic augmentation of rapamycin-induced autophagy in malignant glioma cells by phosphatidylinositol 3-kinase/protein kinase B inhibitors. Cancer Res 65: 3336-3346, 2005.

44. Chaachouay H, Ohneseit P, Toulany M, Kehlbach R, Multhoff G and Rodemann HP: Autophagy contributes to resistance of tumor cells to ionizing radiation. Radiother Oncol 99: 287-292, 2011.

45. Degtyarev M, De Mazi è re A, Orr C, et al: Akt inhibition promotes autophagy and sensitizes PTEN-null tumors to lysosomotropic agents. J Cell Biol 183: 101-116, 2008.

46. Puyal J, Ginet V, Grishchuk Y, Truttmann AC and Clarke PG: Neuronal autophagy as a mediator of life and death: contrasting roles in chronic neurodegenerative and acute neural disorders. Neuroscientist 2011. doi: 10.1177/1073858411404948. 